\title{
Diretrizes curriculares nacionais para os cursos de nutrição: avanços, lacunas, ambiguidades e perspectivas
}

\author{
Curricular guidelines for nutrition \\ courses: advances, ambiguities, \\ omissions and perspectives
}

Nadia Tavares SOARES ${ }^{1}$

Adriana Cavalcanti de AGUIAR²

RE S U M O

As orientações curriculares e pedagógicas para a formação do profissional de nutrição receberam influência da dinâmica das transformações do ensino superior no Brasil. Em 2001, o Ministério da Educação instituiu as diretrizes curriculares nacionais para os cursos de graduação da área da saúde, em consonância com a Lei de Diretrizes e Bases da Educação. As diretrizes curriculares conformam uma nova baliza para o ensino em saúde a partir da extinção do currículo mínimo, considerado demasiadamente teórico, rígido e inflexível, não atendendo às exigências particulares de cada região, instituição ou curso, bem como às demandas sociais. As diretrizes curriculares representam ainda o desejo de superação da hegemonia do modelo biomédico e do ensino centrado no professor. O objetivo deste artigo é analisar criticamente os conteúdos das diretrizes curriculares para a graduação em nutrição e refletir sobre avanços, ambiguidades e lacunas, na perspectiva de uma implementação participativa e de avaliações constantes. O texto discute perfil do egresso, competências e habilidades e conteúdos de estudo, apontando para novas discussões sobre o que está proposto, fomentando possíveis cenários para o aperfeiçoamento do processo da formação em nutrição.

Termos de indexação: Currículo. Nutricionista. Educação superior.

A B S T R A C T

The curricular and pedagogical guidelines for the formation of dieticians were influenced by the dynamic changes that occurred in higher education in Brazil. In 2001, the Ministry of Education instituted the national curricular guidelines for undergraduate health-related courses, in agreement with the Law of Education

\footnotetext{
1 Universidade Estadual do Ceará, Curso de Nutrição, Programa de Mestrado em Saúde Pública. Av. Paranjana, 1700, Campus do Itaperi, 60740-903, Fortaleza, CE, Brasil. Correspondência para/Correspondence to: N.T. SOARES. E-mail: <nadiatsoares@gmail.com>.

${ }^{2}$ Universidade Estácio de Sá, Curso de Medicina. Rio de Janeiro, RJ, Brasil.
} 
896 | N.T. SOARES \& A.C. AGUIAR

Guidelines and Fundamentals. These guidelines represented a new landmark for health-related education since it abolished the minimum curricular requirements, which were considered excessively theoretical and inflexible and did not meet the specific requirements of each region, institution or course, and the social demands. The curricular guidelines also represent the desire to overcome the hegemony of the biomedical model and the teacher-centered education. The goal of this article is to critically analyze the contents of the curricular guidelines for undergraduate nutrition courses and discuss its advances, ambiguities and omissions in order to achieve participatory implementation and constant assessments. The paper discusses professional profiles, competencies and skills, as well as course contents, and suggests new discussions about the proposals, incentivizing achievable scenarios that improve the formation of nutrition.

Indexing terms: Curriculum. Nutritionist. Education, higher.

\section{N T R O D U Ç Ã O}

A palavra currículo, de origem latina curriculum -, significa carreira, curso, ou o ato de correr, e pressupõe a forma e o modo de efetuar um percurso. Na área da educação, seu sentido tem variado ao longo do tempo em função da "concepção de educação e escola e, também, das necessidades de determinada sociedade num dado momento histórico"1 (p.50). Numa abordagem sociológica, é grande a produção teórica sobre a relação entre currículo, sociedade e cultura, com ênfase nas implicações sociais e políticas de deter-minadas opções encaminhadas pelas instituições de ensino ${ }^{2,3}$. Tradicionalmente, porém, currículo significa a relação de disciplinas ou matérias - com um corpo de conteúdos ou de conhecimentos a serem transmitidos -, organizada de forma lógica e sequencial, observando determinado quantitativo de carga horária ${ }^{1,4}$. Em muitos casos, a apresentação do termo currículo ainda significa uma sucessão de disciplinas 5 .

Na década de 1960, o Conselho Federal de Educação (CFE) fixou o currículo mínimo para diversos cursos de graduação do país, listando "matérias que deveriam ser desdobradas em disciplinas para compor o currículo pleno do curso de graduação oferecido em cada instituição" 6 (p.2). A obrigatoriedade de requisitos mínimos de duração e conteúdos fixados visava, supostamente, asse-gurar "um mínimo qualitativo na formação do profissional e, também, um mínimo de homogeneidade entre cursos equivalentes"7 (p.1). Segundo Costa, na década de 1960, os currículos adotados pelos diferentes cursos de nutrição "apresentavam uma grande diversidade estrutural, o que ocasionou a necessidade de uniformização curricular"8 (p.11).

Na década de 1970, o currículo mínimo da nutrição foi revisto sob a crítica de não acompanhar o desenvolvimento técnico e científico e não atender as necessidades da realidade brasileira. Essa crítica se estendeu por décadas, visto que as reformas procedidas não foram capazes de gerar as mudanças esperadas ${ }^{9,10}$. O questionamento quanto à qualidade da formação acontecia também em outros cursos da área da saúde, como medicina ${ }^{11}$ e enfermagem ${ }^{12}$, culminando em severas críticas ao currículo mínimo: demasiadamente teórico, rígido, e inflexível, não atendendo às exigências particulares de cada região, instituição ou curso, bem como às necessidades sociais produzidas pelas desigualdades e peculiaridades do nosso país ${ }^{13}$. Além disso, o currículo mínimo desincentivava a incorporação de novas tecnologias e conhecimentos, desconsiderando a necessidade da aprendizagem ativa, na qual o aluno se torna agente partícipe da sua formação ${ }^{13}$.

O modelo curricular hegemônico na saúde é ainda criticado também pela forte influência que recebe dos estudos Flexner ${ }^{11}$, cuja operacionalização ampla veio a constituir o "paradigma flexneriano", que enfatiza uma formação fortemente biológica, hospitalocêntrica, focada no indivíduo, baseada em aulas predominantemente teóricas e no acúmulo de conhecimentos "especializados", ou seja, fragmentados, sustentados pela organização disciplinar dos currículos e pela separação entre ciclo básico e profissional11 . 
O debate sobre a formação inadequada dos profissionais de saúde e sobre a necessidade de modificações nas orientações curriculares tem sido intensificado no Brasil, pelo advento da reforma sanitária e pelas demandas da implementação do Sistema Único de Saúde (SUS). O debate enfatiza a elaboração, execução e avaliação participativa (gestores, professores e alunos) de métodos e estratégias pedagógicas inovadoras, valorizando o vínculo entre as universidades e os serviços de saúde, bem como a inclusão do princípio da integralidade como um eixo da formação em saúde. Considera também a complexidade, as implicações políticas e os desafios acadêmicos que envolvem a transformação do sistema educacional dominante ${ }^{14-16}$.

Oportunidades de mudanças são criadas com a promulgação, em 1996, da Lei de Diretrizes e Bases da Educação (LDB), que atribui às universidades, no exercício de sua autonomia, a competência de "fixar os currículos dos seus cursos e programas, observadas as diretrizes gerais pertinentes" - item II do Art. $53^{017}$ (p.22).

Nessa direção, em 1997, o Ministério da Educação (MEC) estabeleceu regras para que todas as Instituições de Ensino Superior (IES) do país enviassem propostas para a elaboração das Diretrizes Curriculares Nacionais dos Cursos de Graduação ${ }^{18}$. Várias audiências públicas possibilitaram a discussão das Diretrizes Curriculares (DC), em âmbito nacional e regional.

Em 26 de junho de 2001, especificamente, foi realizada a Audiência Pública no Conselho Nacional de Educação, quando, através do Parecer n 1133/2001-CNE, o MEC apresentou a versão preliminar das DC para os cursos de medicina, enfermagem e nutrição ${ }^{12}$. Na oportunidade, o Conselho Federal de Nutricionistas (CFN) encaminhou a proposta das DC para os cursos de nutrição, discutida em todo o Brasil, com a participação da Associação Brasileira de Nutrição (ASBRAN), de universidades, e comissão de especialistas de ensino da nutrição do MEC ${ }^{19}$.

Posteriormente, a partir da sistematização das propostas discutidas e enviadas, as DC Na- cionais dos cursos de graduação em nutrição, medicina e enfermagem foram aprovadas pelo parecer CES/CNE n 1133/2001, sancionado em 7 de agosto de 2001. Esse parecer foi transformado, posteriormente, na resolução no 5/2001 (DOU de 9/11/2001), que institui as Diretrizes Curriculares Nacionais (DCN), do curso de graduação em nutrição em substituição ao currículo mínimo ${ }^{19,20}$

O objetivo deste trabalho é analisar os avanços que as DCN representam em relação ao extinto currículo mínimo, e também gerar reflexões sobre algumas ambiguidades e lacunas, na perspectiva de uma implementação ativa, assentada no monitoramento e avaliações constantes.

\section{Avanços, ambiguidades, lacunas e perspectivas das diretrizes curriculares nacionais para os cursos de nutrição}

De modo geral, o texto das DCN chama atenção por sua conformação diferenciada em relação ao extinto currículo mínimo. O conteúdo principal não está mais centrado em matérias, duração e carga horária, mas no delineamento do perfil profissional, dos princípios que devem reger a prática do nutricionista, bem como na discriminação das competências e habilidades requeridas. Inclui elementos que direcionam uma estruturação mais qualitativa do curso, voltada para tornar o aluno mais apto para compreender e atuar diante das necessidades de saúde da população.

Dentre as inovações propostas, destacam-se: a) o estímulo à realização de atividades complementares (estágios, cursos, monitorias, projetos de extensão), que devem ocorrer ao longo do curso; b) flexibilização do regime de oferta das disciplinas (seriado semestral, seriado anual, créditos, módulos); c) incorporação de exigências para a gestão do curso, como a elaboração participativa do projeto pedagógico e d) direcionamento para uma distribuição equitativa da carga horária de estágio (20\% do total) nas três principais áreas de atuação do nutricionista (nutrição 
clínica, nutrição social, administração de refeições coletivas). A omissão da carga horária mínima total gerou protestos por parte do CFN, que defende a incorporação de $4000 h^{21}$ na diretriz curricular.

As DCN também abordam as avaliações do desempenho dos alunos, que deverão incluir competências, habilidades e conteúdos curriculares, e incentivam a autoavaliação do próprio curso, em consonância "com o sistema de avaliação e a dinâmica curricular definidos pela Instituição de Ensino Superior (IES)"20 (p.5).

Na discussão que se segue, priorizamos a análise de quatro artigos das DCN: o art. $3^{\circ}$, que descreve o perfil profissional do egresso; os art. $4^{\circ}$ e $5^{\circ}$, que discorrem sobre as competências e as habilidades gerais e específica requeridas do nutricionista; e o art. $6^{\circ}$, que descreve os conteúdos de estudo.

\section{Perfil profissional}

As DCN caracterizam o perfil do egresso do curso de nutrição, reforçando a formação generalista e ampliando suas competências e espectro de atuação, com menção à segurança alimentar e licenciatura em nutrição:

I- Nutricionista, com formação generalista, humanista e crítica, capacitado a atuar, visando à segurança alimentar e à atenção dietética, em todas as áreas do conhecimento em que alimentação e nutrição se apresentem fundamentais para a promoção, manutenção e recuperação da saúde e para a prevenção de doenças de indivíduos ou grupos populacionais, contribuindo para a melhoria da qualidade de vida, pautado em princípios éticos, com reflexão sobre a realidade econômica, política, social e cultural; II - Nutricionista com Licenciatura em Nutrição capacitado para atuar na Educação Básica e na Educação Profissional em Nutrição20 (p.1).

Embora atuar em ações de segurança alimentar não seja uma atribuição nova para os nutricionistas, ela aparece pela primeira vez explícita na orientação curricular nacional de nutrição. Vale destacar que, tradicionalmente, a "atenção dietética" constituía a principal proposta de núcleo específico do saber do nutricionista ${ }^{22}$ e ponto central na identidade profissional e sua percepção pela sociedade ${ }^{23}$. Portanto, a explicitação da Segurança Alimentar (e Nutricional) como uma das principais missões do nutricionista abre novas possibilidades de construção da identidade profissional e novas práticas em nutrição.

Por outro lado, perfis estabelecidos na década de 1980 explicitavam o nutricionista como profissional de saúde: "O Nutricionista é um profissional generalista, de saúde, de nível superior, com formação em Nutrição e Dietética"9 (p.373). Lidos, isoladamente, poder-se-ia argumentar que as DCN não enfatizam esse marco da formação, podendo enfraquecer a identidade profissional, que já é conflituosa, principalmente, para os profissionais que atuam na área de nutrição em unidades de alimentação ${ }^{24}$. Um aspecto característico dos perfis profissionais anteriores, e que permanece, é a identificação do nutricionista como profissional da área de alimentação e nutrição, porém com alguns aspectos formativos que não são exclusivos da categoria. Dentre eles, chama atenção a "formação generalista", por ser ambígua. Tradicionalmente, no ensino da nutrição, o termo é aplicado à formação de profissionais aptos a atuarem em todas as áreas da nutrição, com ênfase nas grandes áreas (nutrição clínica, nutrição social, administração de refeições coletivas) ${ }^{9}$.

O termo pode ser ainda interpretado como ausência de uma especialização, como formação genérica ou ainda superficial. Segundo Bosi, o nutricionista quando define sua formação como generalista não o faz no plano das generalidades e pouca especificidade, mas sim da amplitude e abrangência do conhecimento ${ }^{22}$. Entretanto, a concepção tradicional da formação generalista em nutrição, organizada em função das áreas de atuação, foi questionada em estudo realizado com professores nutricionistas dos cursos de nutrição 
do Ceará25. O estudo reflete que a valorização de uma gama mais ampla de competências não seria o cerne do interesse dessa formação, mas sim a garantia de maior inserção e mobilidade no mercado de trabalho. Porém, na prática, a formação generalista estaria fortalecendo a construção/manutenção de pequenas especializações, com foco na área clínica e desenvolvimento superficial de conhecimentos, habilidades e técnicas das demais áreas de atuação, o que dificilmente prepararia o egresso para os desafios cognitivos e político-institucionais a serem enfrentados nas décadas vindouras ${ }^{25}$.

À luz da homologação das DCN, Lima argumenta que:

A mudança de formação generalista para formação geral talvez expresse o que se pretende fazer de uma forma mais adequada, já que o caráter geral da formação se refere tanto a uma base filosófica que fundamenta a ideia de humanismo como a um conjunto de conhecimentos que possibilitaria o domínio da argumentação e das práticas ${ }^{26}$ (p.63).

Para Deluiz, a formação geral compreende "preparar o profissional competente e o cidadão socialmente responsável, o sujeito-político comprometido com o bem-estar coletivo" 27 (p.1).

Assim, repensar mudanças no ensino da nutrição, a partir da reflexão sobre a concepção da formação generalista, pode significar investir no desenvolvimento de competências gerais, várias delas destacadas nas DCN.

Uma outra possível inconsistência presente na descrição do perfil do egresso diz respeito à expressão "capacitado a atuar ... em todas as áreas do conhecimento"20 (p.1), colocando a ênfase da graduação do nutricionista na produção do conhecimento em diferentes áreas de estudo e pesquisa, ao passo que, pelo contexto, o termo "áreas do conhecimento" poderia ser interpretado como áreas de atuação do nutricionista.

Tanto a graduação como os cursos de pós-graduação constituem o "lugar natural da produ- ção de conhecimento"28 (p.12) e a produção do conhecimento sistemático e legitimado envolve uma retroalimentação entre graduação e pós-graduação. Porém, aos cursos de graduação compete a ênfase no preparo de pessoas "com capacidade para transformar o conhecimento científico em condutas profissionais e pessoais na sociedade, relativas aos problemas e necessidades dessa sociedade" 28 (p.12).

Para as entidades brasileiras de fomento à pesquisa, área do conhecimento é um "conjunto de conhecimentos inter-relacionados, coletivamente construído, reunido segundo a natureza do objeto de investigação com finalidades de ensino, pesquisa e aplicações práticas" 29 (p.2). Em 2005, o Conselho Nacional de Desenvolvimento Científico e Tecnológico (CNPq) divulgou a versão preliminar de um documento que atualiza a classificação das áreas de conhecimento, propondo oito grandes áreas: Ciências Matemáticas e Naturais, Engenharias e Computação, Ciências Biológicas, Ciências Médicas e da Saúde, Ciências Agronômicas e Veterinárias, Ciências Humanas, Ciências Socialmente Aplicáveis, Linguagem e Artes. Essas áreas se dividem em subáreas, sendo a nutrição uma das treze inclusas na grande área Ciências Médicas e da Saúde ${ }^{29}$.

Diferentemente de área do conhecimento, segundo Botomé \& Kubo ${ }^{28}$, o campo de atuação teria como núcleo do conceito:

$$
\begin{aligned}
& \text { Intervir nos problemas e necessidades so- } \\
& \text { ciais, mudar as situações indesejáveis exis- } \\
& \text { tentes. Definido pelas necessidades sociais } \\
& \text { e pelas possibilidades de atuação em } \\
& \text { relação a elas. A referência delimitadora } \\
& \text { não são técnicas, atividades ou instru- } \\
& \text { mentos, mas um fenômeno nuclear de } \\
& \text { atuação e as possibilidades de intervenção } \\
& \text { sobre ele ...28 (p.13). }
\end{aligned}
$$

De acordo com Domingos, confundir "área do conhecimento com disciplina curricular, campo de aplicação do conhecimento, formação profissional e finalidades da atividade científica" 30 (p.31) é algo bastante corriqueiro no meio acadêmico. Contudo, a ausência de concepções 
claras pode acarretar "um sério comprometimento da direção, da organização, da estruturação, da administração e da qualidade do trabalho das universidades e das demais instituições de ensino superior" 28 (p.13). Ou seja, conceitos têm implicações sobre as práticas sociais ${ }^{31}$.

Cabe às instituições formadoras viabilizar a constituição de fóruns para analisar as inconsistências conceituais do perfil de formação do nutricionista proposto pelas DCN e suas implicações para a conformação de seus projetos político-pedagógicos.

A seguir passamos a discutir as competências propostas pelas DCN, implicadas ao adequado exercício profissional do egresso.

\section{Competências e habilidades profissionais, segundo as diretrizes curriculares nacionais para os cursos de nutrição}

Diferentemente do currículo mínimo, as DCN preconizam no Art. $5^{\circ}$ uma organização curricular direcionada para o desenvolvimento de habilidades e competências necessárias à adequada atuação profissional.

Tal como se observa nas DC dos demais cursos da área de saúde, a formação em nutrição inclui como objetivo possibilitar aos graduandos o exercício das seguintes competências e habilidades gerais: Atenção à Saúde, Tomada de Decisões, Comunicação, Educação Permanente, Administração e Gerenciamento. Sua descrição aponta para o equacionamento entre o saber, o saber fazer e o saber ser na prática profissional, princípio que deve estar assegurado na definição das estratégias pedagógicas dos cursos ${ }^{20}$.

É curioso observar que, em determinadas partes, a descrição das competências gerais extrapola aquelas capacidades e atributos a serem desenvolvidos nos cursos de graduação, com expressões como "os profissionais devem" 20 , "Os profissionais de saúde deverão" 20 (p.2) ou "cada profissional deve"20(p.2). Assim, embora louvável, o esforço de estabelecer competências gerais, por vezes, revela impropriedades. Chama atenção na descrição da competência Tomada de Decisões que deliberações sobre alimentos e alimentação, afeitas ao trabalho do nutricionista, não apareçam, mas ainda constem "decisões visando ao uso apropriado ... de medicamentos..." 20 (p.2), que extrapolam a alçada de várias profissões da saúde, incluindo a nutrição. É possível que a maior articulação de carreiras como Medicina, Enfermagem e Farmácia tenha contribuído para essa ênfase equivocada.

Observa-se também que a descrição das competências e habilidades (gerais e específicas) está conformada em forma de lista e que a redação das específicas sugere uma apropriação das competências e habilidades como equivalentes a procedimentos ou ainda atribuições e atividades a serem executadas pelo nutricionista.

O termo "competência" é polissêmico e sua proposição no campo da educação é controversa. Na verdade, o seu sentido está em elaboração e gera muita discussão, porque a partir da entrada em vigência da LDB/1996, o ensino por competências passou a ser palavra de ordem no Brasi $^{32}$. Talvez, por isso, as DCN prescrevam uma lista de competências e habilidades (gerais e específicas), sem distinguir os termos utilizados.

Na literatura consultada ${ }^{33-36}$, os termos competências e habilidades muitas vezes são usados de modo intercambiável, parecendo tênue a linha que os separa. Segundo Perrenoud, a noção de habilidade é bastante ambígua, por vezes designa um saber fazer, por outras "um esquema com uma certa complexidade, existindo no estado prático, que procede em geral de um treinamento intensivo...", ou ainda "uma competência elementar, ou uma parte da ação manual" 33 (p.27). Uma habilidade "pode funcionar como recurso mobilizável por uma ou mais competências de nível mais alto" ${ }^{33}$ (p.27). De maneira mais abstrata, a competência seria "a faculdade de mobilizar um conjunto de recursos cognitivos - saberes, capacidades, informações etc. - para solucionar com 
pertinência e eficácia uma série de situações" 37 (p.1).

$\mathrm{Na}$ introdução dos dezessete itens do art. $5^{\circ}$, o frequente uso de verbos que expressam uma ação ou procedimento - atuar, aplicar, realizar - indica que o fazer prevalece na descrição das competências e habilidades específicas. Porém, é possível localizar exigências implícitas de domínios cognitivos que não se restringem somente a um saber procedimental.

Dentre os verbos que expressam um fazer mais sofisticado, baseado em um domínio cognitivo, complexo, requerido no desenvolvimento das competências e habilidade específicas, destacam-se: analisar, planejar, desenvolver, coordenar, gerenciar, implementar, investigar, avaliar e diagnosticar; como ilustra o item VII do art.50: "avaliar, diagnosticar e acompanhar o estado nutricional; planejar, prescrever, analisar, supervisionar e avaliar dietas e suplementos dietéticos para indivíduos sadios e enfermos"20 (p.2). Portanto, as DCN dão margem a pelo menos duas interpretações distintas sobre as competências e habilidades específicas: uma as reduz ao mero saber fazer, e outra parece incorporar ao saber fazer um conhecimento subtendido. Vale refletir que a competência profissional prescrita socialmente considera o contexto da prática na mobilização das ações.

No que tange à Segurança Alimentar e Nutricional (SAN), chama a atenção que, apesar da visibilidade que as $D C N$ dão a esse espectro da formação na descrição do perfil profissional pretendido, somente em um item do Art. $5^{\circ}$ (item IV), a atuação em políticas e programas de SAN é explicitamente citada: "atuar em políticas e programas de educação, segurança e vigilância nutricional, alimentar e sanitária, visando à promoção da saúde em âmbito local, regional e nacional"20 (p.2). Fica em aberto como deve ser essa atuação: liderança e formulação ou mera participação? Outros itens são mais explícitos, por exemplo, o item precedente (III) especifica a inserção do nutricionista no âmbito da educação: ele deve "desenvolver e aplicar métodos e técnicas de ensino em sua área de atuação"20 (p.2). O verbo desenvolver implica atitude ativa e criativa na produção de tais técnicas e métodos, superando sua mera aplicação. Já o item V explicita a "formulação de propostas" para a educação nutricional. Ou seja, as DCN fomentam maior protagonismo do egresso em atividades relativas à educação do que nas políticas de alimentação e nutrição (apesar de a educação nutricional ser um componente importante). Por outro lado, o item $\mathrm{X}$ refere à competência de "atuar em equipes multiprofissionais destinadas a planejar, coordenar, supervisionar, implementar, executar e avaliar atividades na área de alimentação e nutrição e de saúde" 20 (p.2), subentendendo que o nutricionista possa exercer liderança desde que acompanhado por outros profissionais não nutricionistas, apesar de as ações mencionadas serem características da área de nutrição.

Contrapondo o conteúdo das competências e habilidades específicas com o das gerais, observa-se que as específicas não exploram desdobramentos das gerais na especificidade do campo de atuação do nutricionista, principamente no que se refere a preparar o nutricionista para liderar, administrar, gerenciar, comunicar e tomar decisões em SAN. Isso se explica, talvez, porque o estabelecimento das competências e habilidades teve no SUS o seu eixo central, como expressa o Parágrafo Único: "A formação do nutricionista deve contemplar as necessidades sociais da saúde, com ênfase no Sistema Único de Saúde (SUS)" 20 (p.2). Porém, se considerarmos que as políticas e as práticas de SAN e os seus princípios norteadores ${ }^{38}$ têm natureza intersetorial, as DCN podem ser interpretadas como pautadas em uma visão limitada dos campos de inserção do nutricionista.

O foco no SUS procede na perspectiva do nutricionista reconhecer-se como um profissional de saúde. Mas o conceito e a abrangência da SAN evidenciam que a atuação do nutricionista deve estar articulada com as políticas públicas, estando implicada na promoção da saúde, na prevenção e tratamento das doenças, em diferentes insti- 
tuições e setores. Desse modo, esse profissional de saúde pode e deve atuar com a produção de alimentos, vigilância sanitária, fiscalização, industrialização, comercialização, visando a reforçar o foco na saúde e não apenas na doença.

A problematização das $\mathrm{DCN}$ acentua, portanto, que o texto não aborda o papel de liderança e de integração de diferentes dimensões que o egresso de nutrição teria que desenvolver para atuar na perspectiva da SAN. Pelo contrário, enfatiza a formação direcionada para o SUS, possibilitando fortalecer a visão restrita do ensino, dos campos de estágio, bem como da inserção e das ações profissionais. Não fica claro no texto das DCN como os princípios da SAN incorporam os do SUS e projetam a formação do egresso de nutrição para além do setor saúde.

Por outro lado, o direcionamento da formação para o SUS por si expressa um ideal desafiador, considerando que essa instância ainda não constitui local privilegiado de inserção do nutricionista e, por conseguinte, de interação ativa do aluno de graduação com o profissional em serviço. A maioria dos profissionais está atuando nas áreas clínica e de alimentação coletiva do setor privado $^{39,40}$. Segundo estudo conduzido pelo CFN, apenas $18,4 \%$ dos nutricionistas em exercício mantêm vinculo com o SUS ${ }^{39}$. Além disso, embora, em vários estados e municípios, nutricionistas estejam lotados em algumas unidades básicas - hospitais, ambulatórios especializados e estruturas centrais $^{41}$-, isso não significa que haja inserção sistemática do profissional em todo os níveis de responsabilidade do SUS. Em Campinas, por exemplo, Pádua \& Boog ${ }^{42}$ retratam que a inclusão do nutricionista na rede básica é insipiente, implicando prejuízos para implementação das ações de promoção à saúde. Assis et al. ${ }^{43}$ também salientam incoerências inerentes à ausência do nutricionista no Programa de Saúde da Família.

Assim, a prescrição da ênfase da formação centrada no SUS pode ser melhor compreendida na ótica de uma diretriz que corrobora o anseio dos nutricionistas pelo desenvolvimento de iniciativas que possam modificar tanto a formação do egresso de nutrição como o perfil da atenção à saúde, principalmente na rede básica, espaço relevante e estratégico para construção de ações articuladas, visando à realização da SAN.

\section{Conteúdos de estudo}

Os conteúdos propostos pelas DCN para o desenvolvimento das competências e habilidades gerais e específicas estão organizados de acordo com as seguintes áreas: ciências biológicas e da saúde, ciências sociais, humanas e econômicas, ciências da alimentação e nutrição, e ciência dos alimentos ${ }^{20}$. A estrutura dessa orientação difere do currículo mínimo por não apresentar a linha divisória entre ciclo básico e profissional. Um ponto convergente, além da manutenção da orientação dos próprios conteúdos de estudo, é sua inclinação à concepção clínica e epidemiológica da atenção à saúde ${ }^{26,44}$. Chamam também atenção lacunas de conteúdos relativos ao desenvolvimento de algumas competências e habilidades, como, por exemplo, os conhecimentos relacionados ao desenvolvimento de liderança, tomada de decisões, administração, gerenciamento e empreendedorismo. Capacitações inter-relacionadas que desafiam as IES nos dias atuais $^{45}$ e que são imprescindíveis para o desenvolvimento de uma região, de produtos e serviços $^{46}$.

Observa-se também que a orientação do estudo dos alimentos, da alimentação e da sua interação com a vida não alcança uma dimensão extensiva à cultura, aos aspectos históricos e políticos ${ }^{44}$ e não contempla as questões macro e abrangentes que permeiam a dinâmica da cadeia alimentar produtiva, o que envolve fatores sociais, econômicos, políticos, agrícolas, comerciais, legais, ecológicos, ambientais, geográficos e culturais, dentre outros.

Igualmente não está claro que o aparelho formador deva adotar concepção mais ampla de promoção da saúde, vinculada ao desenvolvimento sustentável e na qual as principais ações ocorram no nível das macropolíticas, priorizando 
nas análises as desigualdades sociais e econômicas - pobreza, degradação do ambiente -, que influenciam o bem-estar da população. Falta também direcionamento para o estudo de métodos de pesquisa e avaliação, de modo que os estudantes de nutrição desenvolvam a capacidade de elaboração, implementação e avaliação de planos, programas, projetos e ações na perspectiva da realização do direito humano à alimentação adequada.

Em suma, a omissão de alguns conteúdos-chave e certo descompasso entre o discurso e a realidade do mercado de trabalho sugerem limitações e desafios para o alcance da formação do profissional almejado para o egresso de nutrição. Quando se trata de compreender e atuar nas políticas e programas de SAN, essa formação apresenta certa fragilidade em relação às orientações que visam sustentar essa "nova" perspectiva de atuação.

\section{CONSIDERAÇÕES FINAIS}

As DCN representam hoje o que há de mais atualizado em termos de regulamentação para a graduação em nutrição em âmbito nacional. A seu favor cooperaram reflexões e sugestões da própria categoria, com participação das universidades, após anos de reflexão, debate e proposições. Em decorrência disso, é esperável que muitos cursos tenham avançado qualitativamente na definição de seus projetos pedagógicos. Porém, as DCN podem não ter contemplado de maneira plena o ideário de todos os interessados na sua construção, mas, sem dúvida, marcam uma nova fase do currículo de nutrição.

As DCN, como instrumento oficial de balizamento dos projetos pedagógicos dos cursos, devem ser consideradas na criação de cursos de nutrição e avaliação/reformulação dos já instituídos. Sua implementação não deveria, entretanto, ser conduzida mediante incorporação passiva de uma receita, mas, sim, como uma oportunidade para novas discussões sobre o que está proposto, fomentando o aperfeiçoamento do processo da formação em nutrição.
A implantação adequada demanda condições de trabalho, capacitação e educação permanente para os docentes e carga horária coletiva para aprofundar discussões sobre competências, perfil e ênfases da formação, visando a "reconstrução coletiva", com a participação de alunos e professores, do currículo, do processo ensino-aprendizagem e da avaliação. É preciso dedicar tempo à desconstrução das premissas da formação, que informam a operacionalização do currículo, do processo ensino-aprendizagem e avaliações, e analisar os possíveis avanços, retrocessos, acertos, incoerências, lacunas e perspectivas.

Por fim, a orientação da formação em nutrição deveria primar e exprimir um processo de ensino-aprendizagem capaz de colocar no mercado de trabalho profissionais preparados para compreender, analisar e intervir na busca da justiça social, que implica saúde e SAN como direito de cidadania.

\section{COLABORADORES}

N.T. SOARES foi propositora da temática abordada no artigo, levantamento bibliográfico, análise crítica da literatura revisada e construção do texto do artigo. A.C. AGUIAR participou da análise crítica da literatura revisada, construção do texto do artigo.

\section{REFERÊ NCIAS}

1. Piletti C. Didática geral. $22^{a}$ ed. São Paulo: Ática; 1999.

2. Forquin JC. Escola e cultura: as bases sociais e epistemológicas do conhecimento escolar. Porto Alegre: Artes Médicas; 1993.

3. Moreira AF, Silva TT, organizadores. Currículo, cultura e sociedade. São Paulo: Cortez; 1994.

4. Smith MK. Curriculum theory and practice' the encyclopedia of informal education. 2000 [cited 2009 Sept 17]. Available from: <www.infed.org/ biblio/b-curric.htm>.

5. Feuerwerker LCM. Gestão do processo de mudança na graduação em medicina. In: Marins JJN, Rego S, Lampert JB, Araújo JG, organizadores. Educação médica em transformação: instrumentos para a 
construção de novas realidades. São Paulo: Hucitec; 2004. p.1-39.

6. Brasil. Ministério da Educação. Conselho Nacional de Educação. Parecer CNE/CES 103, de 19 de abril de 2007. Dispõe sobre aproveitamento de estudos em caso de transferência de estudantes entre instituições de educação superior. Brasília; 2007.

7. Giogertti MF. Histórico e perspectivas para as habilitações do curso de engenharia. Rev Est. [Internet]. 2006 [acesso 2009 set 17]; (22) [aproximadamente 8p]. Disponível em: <http://www.abmes.org.br/ Publicacoes/Estudos/22/est22-08.htm>.

8. Costa NSC. Revisitando os estudos e eventos sobre a formação do nutricionista no Brasil. Rev Nutr. 1999; 12(1):5-19. doi: 10.1590/\$1415-52731999 000100001.

9. Associação Brasileira de Nutrição. Histórico do nutricionista no Brasil, 1939 a 1989: coletânea de depoimentos e documentos. São Paulo: Atheneu; 1991.

10. Costa NSC. A formação do nutricionista, educação e contradição. 2ª ed. Goiânia: UFG; 2002.

11. Lampert JB. Tendências de mudanças na formação médica no Brasil: tipologia das escolas. São Paulo: ABEM; 2002.

12. Bagnato MHS, Rodrigues, RM. Diretrizes curriculares da graduação de enfermagem: pensando contextos, mudanças e perspectivas. Rev Bras Enfermagem. 2007; 60(5): 507-12.

13. Maranhão EA. A construção coletiva das diretrizes curriculares nacionais dos cursos de graduação da saúde: uma contribuição para o Sistema Único de Saúde. In: Almeida M, organizador. Diretrizes curriculares nacionais para os cursos universitários da área da saúde. Londrina: Rede Unida; 2003.

14. Feuerwerker LCM. Estratégias para a mudança da formação dos profissionais de saúde. Cad Ensino e Currículo. 2001; 3(4):11-23.

15. Feuerwerker LCM. Impulsionando o movimento de mudanças na formação dos profissionais de saúde. Olho Mágico. 2001; 8(2):4-6.

16. Marins JJN, Rego S, Lampert JB, Araújo JGC, organizadores. Educação médica em transformação: instrumentos para a construção de novas realidades. São Paulo: Hucitec; 2004.

17. Brasil. Lei n 9.394, de 20 de dezembro de 1996. Estabelece as diretrizes e bases da educação nacional. Diário Oficial da União. 1996; 24 dez.

18. Brasil. Ministério da Educação. Secretaria de Educação Superior. Diretrizes curriculares. Edital nº 04/97, de 10 de dezembro de 1997. Brasília; 1997.

19. Calado CLA. A expansão dos cursos de nutrição no Brasil e a nova lei de diretrizes e bases - LDB.
2003. Conselho Federal de Nutricionistas/CFN. [acesso 2009 set 19]. Disponível em: <http://www. cfn.org.br/novosite/pdf/expansao.pdf>.

20. Brasil. Ministério da Educação. Conselho Nacional de Educação. Institui diretrizes curriculares nacionais do curso de graduação em nutrição. Resolução CNE/CES 5, de 7 de novembro de 2001. Diário Oficial da União. 2001; nov 9, Seção 1, p.39

21. Conselho Federal de Nutricionistas. Carga horária dos cursos de nutrição. [acesso 2009 set 17]. Disponível em: <www.cfn.org.br>.

22. Bosi MLM. Profissionalização e conhecimento: a nutrição em questão. São Paulo: Hucitec; 1996.

23. Ypiranga L, Gil MF. Formação profissional do nutricionista: por que mudar? In: Cunha DTO, Rodrigues LY, GIL MF. Seminário nacional sobre ensino de nutrição. Goiânia: FEBRAN, 1989.

24. Lima ES, Oliveira CS Gomes MCR. Educação nutricional: da ignorância alimentar à representação social na pós-graduação do Rio de Janeiro (1980-98). Hist Ciênc Saúde - Manguinhos. 2003; 10(2):602-35.

25. Soares NT. Diretrizes curriculares nacionais para cursos de graduação em nutrição e competências profissionais para atuação em segurança alimentar e nutricional: perspectivas de docentes do Ceará [tese]. Universidade do Estado do Rio de Janeiro; 2007 [acesso 2009 set. 19]. Disponível em: <http:// www.tesesims.uerj. br/lildbi/docsonline/8/1/418Tese_Nadia_Tavares_Soares.pdf>.

26. Lima ES. Comunicação no 1. Problemas concretos, dinâmica e movimentos de mudança nos cursos de nutrição com base nas diretrizes curriculares. Cad CE. 2001; 3(4):62-4.

27. Deluiz N.A. Globalização econômica e os desafios à formação profissional. Bol Téc SENAC. 2004; 30(3):73-9.

28. Botome SP, Kubo OM. Responsabilidade social dos programas de pós-graduação e formação de novos cientistas e professores de nível superior. Interação Psicol. 2002; 6(1):81-110.

29. Conselho Nacional de Segurança Alimentar e Nutricional. Princípios, diretrizes de uma política de segurança alimentar e nutricional. Textos de referência da $2^{\text {a }}$ Conferência Nacional de Segurança Alimentar e Nutricional. Brasília; 2004.

30. Domingos M. "Defesa e segurança" como área de conhecimento científico. Tensões Mund. 2006; (3):51-64.

31. Campos GWS. Saúde pública e saúde coletiva: campo e núcleo de saberes e práticas. Ciênc Saúde Colet. 2000; 5(2):219-30.

32. Prado E. Da formação por competências à pedagogia competente. Rev Múlt Leit. 2009; 2(1):115-130. 
33. Perrenoud P. Construir as competências desde a escola. Porto Alegre: Artmed; 1999.

34. Guedes GG. As habilidades e o pensamento sistêmico: fatores decisivos na formação do administrador. Glob Manag. 2003; (5):45-59.

35. Carvalho I. Ivênio Carvalho, sócio-diretor da Dorsey, Rocha \& Associados e especialista em competências. Comunidade RH. 2003. Entrevista concedida a Camila Micheletti. [acesso 2009 set 19]. Disponível em: <http://carreiras.empregos.com.br/ comunidades/rh/entrevistas/100203-ivenio_ competencias.shtm>.

36. Deluiz N. O Modelo das competências profissionais no mundo do trabalho e na educação: implicações para o currículo. Bol Téc SENAC. 2001; 27(3):13-25.

37. Perrenoud P. Construindo competências. 2000. Entrevista concedida a Paola Gentile e Roberta Bencini. [acesso 2009 set 19]. Disponível em: <http://www.unige.ch/fapse/SSE/teachers/ perrenoud/php_main/php_2000/2000_31.html>.

38. Conselho Nacional de Segurança Alimentar e Nutricional. Princípios, diretrizes de uma política de segurança alimentar e nutricional. Textos de referência da $2^{a}$ Conferência Nacional de Segurança Alimentar e Nutricional. Brasília; 2004.

39. Conselho Federal de Nutricionistas. CFN traça o perfil do nutricionista no Brasil. Brasília; 2006.

40. Akutsu RC. Brazilian dieticians: professional and demographic profiles. Rev Nutr. 2008; 21(1):7-19. doi: 10.1590/S1415-52732008000100002.
41. Bonomo E, Alves OMP. A implantação das diretrizes curriculares nos cursos de graduação em nutrição: avanços e obstáculos - oficina. Olho Mágico. 2005; 12(4):87-91.

42. Padua JG, Boog MCF. Avaliação da inserção do nutricionista na Rede Básica de Saúde dos municípios da Região Metropolitana de Campinas. Rev Nutr. 2006; 19(4):413-42. doi: 10.1590/S1415-52 732006000400001.

43. Assis AMO, Santos SMC, Freitas MCS, Santos JM, Silva MCM. O Programa Saúde da Família: contribuições para uma reflexão sobre a inserção do nutricionista na equipe multidisciplinar. Rev Nutr. 2002; 15(3):255-66. doi: 10.1590/\$1415-527320 02000300001.

44. Santos MMAS. Comunicação no 2. Problemas concretos, dinâmica e movimentos de mudança nos cursos de nutrição com base nas diretrizes curriculares. Cad CE. 2001; 3(4):64-5.

45. Cunha de ANC, Steiner Neto PJ. Considerações sobre a formação da cultura empreendedora dentro da universidade. Rev Cent Ciên Admin. 2005; 11(1):39-50.

46. Barros FSO, Fiúsa JLA, Ipiranga ASR. O empreendedorismo como estratégia emergente de gestão: histórias de sucesso. Rev O\&S. 2005; 12(33):109-28.

Recebido em: 21/10/2008

Versão final reapresentada em: 29/10/2009

Aprovado em: 4/5/2010 
